\title{
委員会報告
}

\section{International Survey on Cleft Palate Speech Evaluation and Categorization}

\author{
Committee on Cleft Palate Speech Japan Society of Logopedics and Phoniatrics \\ (Chairperson : Keiko Okazaki, Ph. D., Supervisor : Masayuki Sawashima, M. D.) Fumiko Tanokuchi ${ }^{3)}$, Tomiko Fukuda ${ }^{4)}$, Mayumi Miura ${ }^{5)}$, Masayuki Sawashima ${ }^{6)}$ \\ Noriko Ainoda ${ }^{1)}$, Keiko Okazaki², Ayako Ohira, Masako Katoh ${ }^{2)}$,
}

\begin{abstract}
The aims of this paper are to survey categorical systems of cleft palate speech that professionals in other countries use in their clinical work and to obtain their opinion of our system usually used in Japan. We sent 217 questionnaires mainly to institutions in the U. S. A. and Canada. Each questionnaire consisted of 3 questions : description of the categorical system used routinely in each institution, types of speech samples used for evaluation, and a request for comments on our system.

Fifty-two institutions (24\%) responded. Almost all answered that the speech factors to be evaluated were vocal resonance and articulation. They also used speech in words, sentences and conversation as speech samples. The three most frequently used articulation tests Bzoch Error Pattern Articulation Test, Templin-Darley Test of Articulation and Goldman-Fristoe Test of Articulation. We received various comments from 23 institutions, with 10 answers showing complete agreement with our system.

This project gave us meaningful information about American/European clinical work on cleft palate speech, leading us to consider our categorical system to be clinically reasonable.
\end{abstract}

Key words : cleft palate speech, categorization, international survey, questionnaire

\section{Introduction}

Speech disorders in cleft palate patients are so characteristic that professionals working with such patients conventionally refer to their speech as "cleft palate speech". To formulate an effective interventional plan, professionals use several categorical systems in their evaluative procedures. In Japan, we usually use the system shown in Table 1. which is distinctive in two points : 1 . it includes new types of misarticulation added to conventional ones, based on our postsurgical monitoring data ${ }^{1 \sim 6)}$; and 2. it describes clearly the relation between types of speech abnormality and VP dysfunction. Although this system has been convenient for clinical purposes, we feel that it is time to discuss and reconsider its significance in the international context. The aims of this project are to survey categorical systems that professionals in other countries use when evaluating speech abnormalities in cleft pal-

${ }^{1)}$ Department of Otolaryngology, Kanazawa Medical University, ${ }^{2)}$ Department of Plastic and Reconstructive Surgery, Showa University, ${ }^{3)}$ Department of Otolaryngology, Kagawa Medical University, ${ }^{4}$ Department of Dentistry, University of Osaka,

${ }^{5)}$ Department of Communicative Disorders, Kumamoto Kinoh Hospital, ${ }^{6)}$ The Yokohama Seamen's Insurance Hospital 
Table 1 Categorical system of articulation problems in the cleft palate

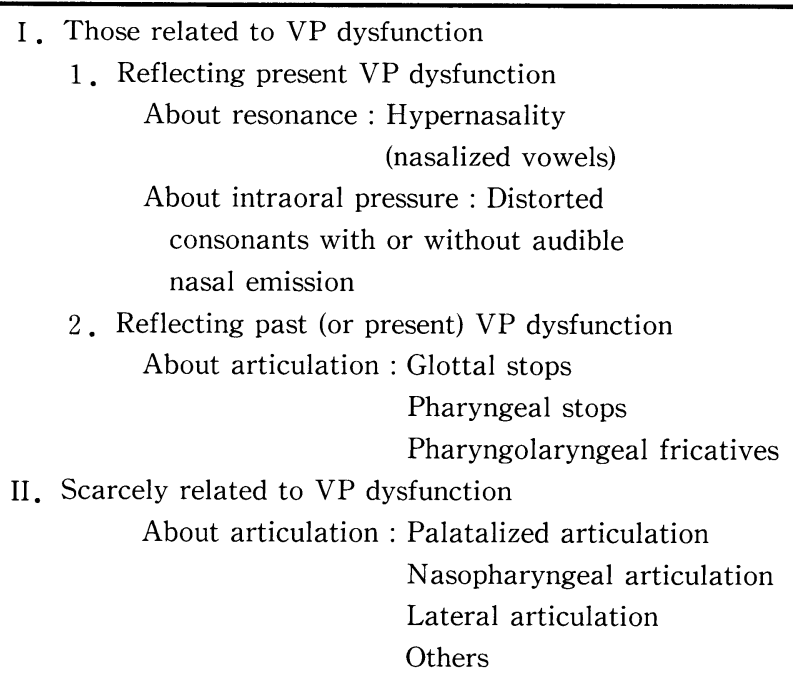

ate patients and to obtain their opinions on our system.

\section{Procedures}

We gathered information by questionnaire from May 1991 through February 1992. A total of 217 questionnaires were sent, mainly to institutions in the U. S. A. and Canada. Adoption of a team-oriented treatment philosophy, according to the membership directory of the American Cleft PalateCraniofacial Association, was a condition of the addressee selection. We also mailed several questionnaires to European institutions, including the office of the Cleft Palate Committee of the International Association of Logopedics and Phoniatrics. Each questionnaire consisted of 3 questions : description of the categorical system used routinely at the institution, types of speech samples used for evaluation, and a request for comments on our categorical system (see Appendix).

\section{Results}

A total of 52 institutions ( $24 \%$ ) responded to the questionnaire. To the first question, 49 institutions answered that speech factors to be evaluated were vocal resonance and articulation. In 42 of $50 \mathrm{com}$ pleted answers (84\%) nasal emission was also an assessment target, and in 20 (40\%) another target



Fig. 1 Speech aspects to be assessed at each institution. ( $\mathrm{R}$ : resonance of voice, $\mathrm{A}$ : articulation, NE : nasal emission, $\mathrm{P}$ : phonation)

was dysphonia (Fig. 1). Twelve answers involved the clinical concept of nasalemission, with one-half considering it as a problem of articulation and the other half as one of vocal resonance.

The cleft palate speech system used at 35 institutions were Bzoch's system (9 institutions), the Pittsburgh University system (7) and original systems (9). The other 8 institutions answered that they 
adopted a system similar to ours (Fig. 2).

The second question was about speech samples and articulation tests. Fifty available answers showed that almost all institutions use speech in words, sentences and conversations, elicited spontaneously or imitatively, as speech samples, depending on patient age. Thirty-nine institutions provided information on the types of articulation tests used routinely : Bzoch Error Pattern Articulation Test in 14 institutions, Templin - Darley Test of Articulation including Iowa Pressure Articulation Test in 13, Goldman-Fristoe Test of Articulation in 12. Eight institutions use original articulation tests. The other 5 use tests such as the Fisher-Logemann Test, Photn-Articulation Test or Arizona Test of Articuilation (Fig. 3). (Note : Total number exceeds 39 because many institutions use multiple test forms.) We received original or copied test sheets from 39 institutions.

The third question was a request for comments on our categorical system. We received various comments from 23 institutions. Ten answers expressed complete agreement with our system. The other 13 expressed some disagreement, but 6 of these were due to not referring to a list of papers attached to

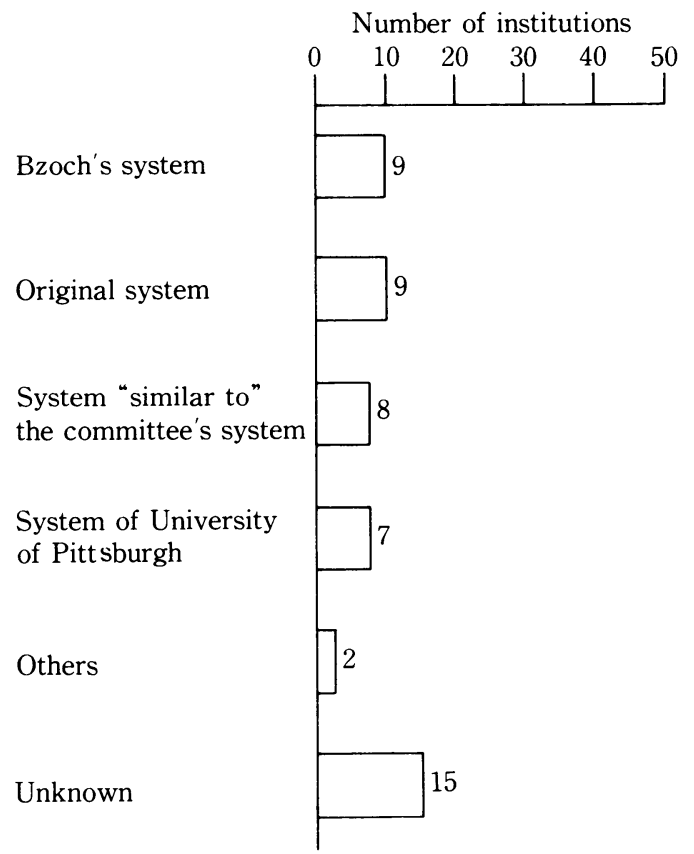

Fig. 2 Systems used in clinical activities. the questionnaire forms. Other opinions focused on the following points : categorization of misarticulations themselves, concept of nasal emission, addition of misarticulation due to phonological delay and malocclusions, addition of dysphonia, and meaning of the terms (Table 2).

\section{Discussion}

That vocal resonance and articulation are the major speech aspects of clinical evaluation in $98 \%$ of the institutions investigated is quite reasonable. If "nasal emission" is added as an assessment target, the percentage of institutions slightly decreases to 84 \%. "Nasal emission" has a long history of having been considered as either an articulation or resonance disorder in the literature ${ }^{7)}$, and it is still an issue to be resolved. We, however, regard it as an articulatory problem. In $40 \%$ of the institutions,

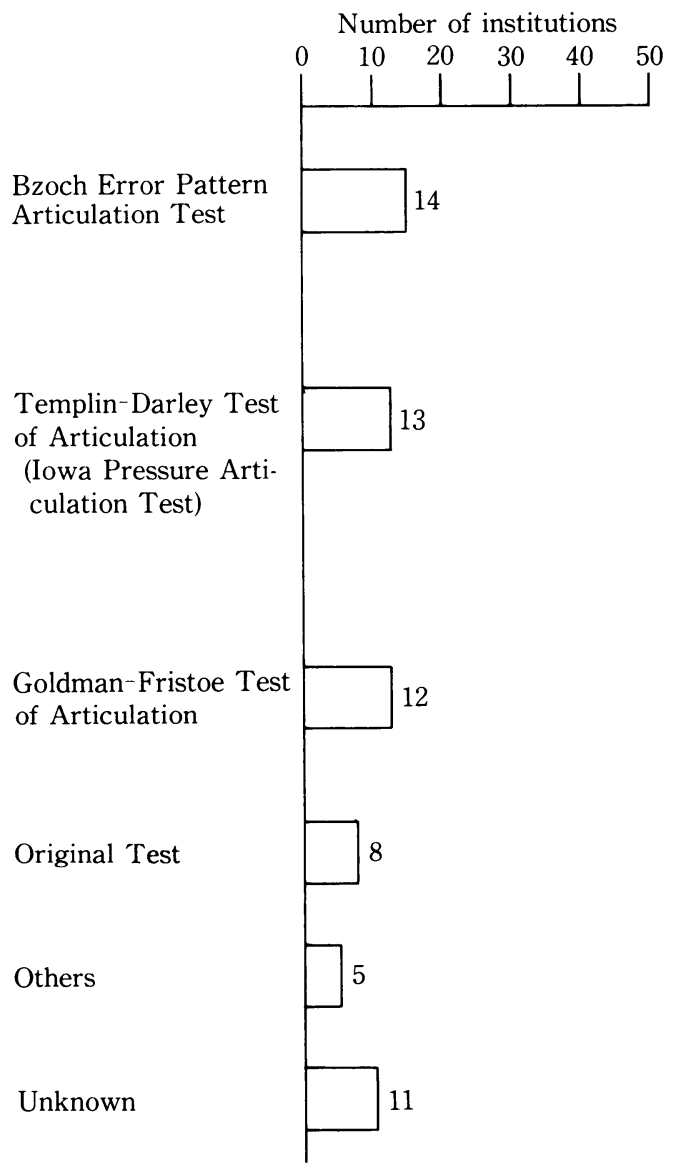

Fig. 3 Articulation tests used in clinical activities. 
Table 2 Comments on our categorical system given by 23 respondents.

\begin{tabular}{lll}
\hline Complete agreement & 10 & \\
Partial agreement or disagreement & 13 & \\
$\quad$ Misunderstanding & & 6 \\
Terminology & 1 \\
Types of abnormal articulation & 1 \\
Concept of nasal emission & 1 \\
Addition of & \\
$\quad$ phonological development & 1 \\
$\quad$ phonatory problems & 1 \\
$\quad$ misarticulation due to malocclusions & 1 \\
"Not detailed, not objective." & 1 \\
\hline
\end{tabular}

phonatory problem is an evaluative speech target. Dysphonia is often observed in cleft palate patients, especially in those with glottal compensatory articulation, but we need more clinical data on whether it appears characteristically in those with cleft palate.

About categorical systems, $70 \%$ of the institutions surveyed use systems including published ones such as Bzoch's system ${ }^{7}$ and that of the University of Pittsburgh ${ }^{8)}$, Bzoch's system was developed for screening cleft palate speech into 6 original categories in 1961, and 11 expanded ones in 1989. The purpose of the categorical system of the University of Pittsburgh, on the other hand, is to decide whether articulatory patterns shown by a patient are indicative of VP dysfunction, dental abnormal ities, or developmental delay. Both the Bzoch's and Pittsburgh systems aim at efficient speech evaluation. Our system is based on a different philosophical concept from these two systems in the sense that it should be used when evaluating a patient's speech in relation to VP function.

A variety of perceptual standard articulation tests, either for screening or diagnostic purposes, are available in the United States. The three most common tests used for cleft palate patients are Bzoch's Error Pattern Articulation Test ${ }^{7)}$, the Templin-Darley Articulation Test involving the Iowa Pressure Articulation Test ${ }^{9)}$ and the Goldman-Fristoe Articulation Test ${ }^{10}$. The first two tests serve cleft palate patients most frequently. Thirty-nine institutions responded to our request to send us the articulation test forms used in routine clinical work.
Most of them are organized systematically and easy to use. They can be a model for us to develop reasonable diagnostic articulation tests for Japanese cleft palate patients.

Trained professional ears can reliably identify abnormal types of speech sounds which are predominant in the cleft palate according to the literature and clinical experience. We tried to classify these deviant articulatory patterns in relation to present or past VP dysfunction. The problem of VP function is a primary concern when evaluating speech abnormality in pre-or postsurgical patients with a variety of palatal cleft types. This classification system contributes to effective treatment plans for each patient's misarticulation including surgical treatment, prosthetic management, or speech therapy. It also provides information useful when considering the etiology of a patient's speech disorder retrospectively.

Factors other than VP function must also cause speech abnormalities, such as palatal morphology, abnormal dental arch, malocclusion, persistent hearing impairment, developmental delay and social problems. However, the causal relation of these factors to each misarticulatory type is more complicated than that of VP function. We limited our categorical system, therefore, to that related only to VP function as a primary step. Problems of phonological development, phonation and malocclusions as noted in several answers should be other important considerations.

A part of this report was orally presented at the 37 th Congress of the Japan Society of Logopedics and Phoniatrics in November 1992. The authors wish to thank all professionals who kindly answered our questionnaire and added their valuable comments.

\section{References}

1) Ainoda, N, Yamashita, K., Tsukada, S. : Articulation at age 4 in children with early repair of cleft palate. Ann. Plast. Surg., 15 : 415-422, 1985.

2) Kawano, M., Isshiki, N., Harita, Y., et al. : Laryngeal fricative in cleft palate speech. Acta Otolaryngol, Suppl, 419 : 180-188, 1985.

3) Abe, M., Sawashima. M. and Okazaki, K. : 
Nasopharyngeal articulation: A particular type of articulation error. Video tape presented at the 20th Congress of the International Association of Logopedics and Phoniatrics, Tokyo, August 1986.

4) Michi, K., Suzuki, N., Yamashita, Y., et al. : Visual training and correction of articulation disorders by use of dynamic palatography : Serial observation in a case of cleft palate. J. S, H. D., 51 : 226-238, 1986.

5) Okazaki, K., Kato, M., Onizuka, T. : Palate morphology in children with cleft palate with palatalized articulation. Ann. Plast. Surg. 26 : 156-162, 1991.

6) Kato, M. : Lateral articulation : Observation of articulatory movement using electro toothpalatography. Jpn. J. Logop. Phoniatr., 32 : 1831, 1991. (Japanese)

7) Bzoch, K. R. : Communicative Disorders Related to Cleft Lip and Palate, College-Hill
Press, 1989.

8) McWilliams, B. J., Morris, H. L., Shelton, R. L. : Cleft Palate Speech, 2nd ed., Philadelphia : B. C. Decker Inc., 1990.

9) Templin, M. C., Darley, F. L. : The TemplinDarley Tests of Articulation, 2nd ed., Iowa City : Bureau of Educational Research and Service, University of Iowa, 1969.

10) Goldman, R. and Fristoe, M. : Goldman-Fristoe Articulation Test. Circle Pines : American Guidance Services, 1986.

11) Trost - Cardamone, J. E. : Coming to terms with VPI : A response to Loney and Bloem. Cleft Palate J., 26 : 68-70, 1989.

Address for correspondence :

Noriko Ainoda, Department of Otolaryngology, Kanazawa Medical University, Uchinada, Ishikawa, 920-02, Japan

\section{APPENDIX}

Questionnaire on Your Categorical System Regarding Articulation Problems Found in Cleft Palate Individuals

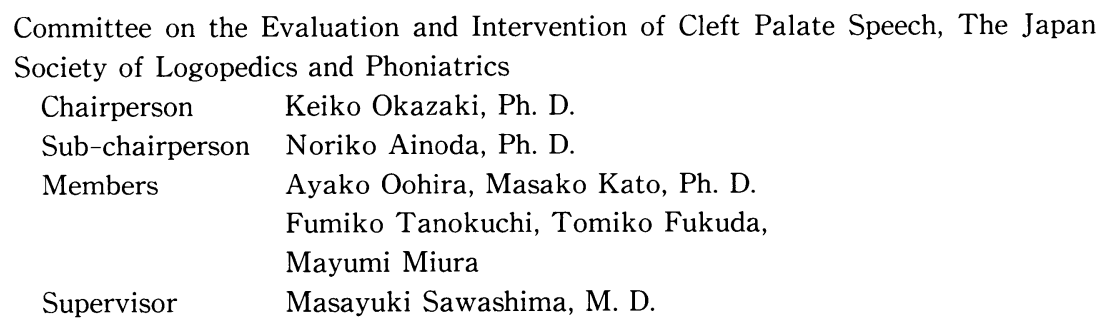

Issues which we have been discussing for these 10 years include clinical evaluation of velopharyngeal function and speech in cleft palate individuals. In 1980 and 1984, we published clinical tests of VP function and speech to help speech-language pathogists evaluate cleft palate speech in daily clinical work. Last year we published a sample tape of cleft palate speech problems according to our categorical system. We also surveyed the present state of cleft palate treatment in Japan and published our findings in 1989 .

The committee is now surveying the categorical systems used for the clinical evaluation of cleft palate individuals' speech problems in different countries. We would like to know your categorical system used in clinical activities.

We sincerely appreciate your kind cooperation with our survey project. Thank you.

1. What categorical system do you use when evaluating cleft palate patients' speech problems? Our 
system is written on the following page.

2. How do you obtain a speech sample from each cleft palate patient?

Speech material :

words/sentences/conversation/others (syllables,

Situation :

spontaneous/repetition/oral reading/others

Would you please send us a copy of the articulation test sheet which you use in clinical evaluations?

3. Please comment on the following categorical system which we usually use in clinical activities.

Articulation problems evaluated auditorily

in the cleft palate ${ }^{1)}$

I. Those related to VP dysfunction

1. Reflecting present VP dysfunction

About resonance : Hypernasality (nazalized vowels)

About intraoral pressure : Distorted consonants with or without audible nasal emission (The articulatory movements are basically normal.)

2. Reflecting past (or present) VP dysfunction :

About articulation : Glottal stops

Pharyngeal stops

Pharyngolaryngeal fricatives ${ }^{2)}$

II. Scarcely related to VP dysfunction

About articulation : Palatalized articulation ${ }^{3)}$

Nasopharyngeal articulation ${ }^{4}$

Lateral articulation ${ }^{5,6}$

Others

References 1) Ainoda, N., Articulation at age 4 in children with early repair of cleft palate, Ann Plast Surg, 15 : 415, 1985.

2) Kawano, M., Laryngeal fricative in cleft palate speech, Acta Otolarygol Suppl. $419: 180,1985$.

3 ) Okazaki, K., Palate morphology in children with cleft palate with palatalized articulation, Ann Plast Surg, 26 : 156, 1991.

4 ) Abe, M., Nasopharyngeal articulation : A particular type of articulation error. Video tape presented at the 20th Congress of the International Association of Logopedics and Phoniatrics, Tokyo, August, 1986.

5 ) Kato, M., Lateral articulation : Observation of articulatory movement using electro tooth-palatography (Japanese). Jpn J Logop Phoniatr, $32: 18,1991$.

6 ) Michi, K., Visual training and correction of articulation disorders by use of dynamic palatography : serial observation in a case of cleft palate. J Speech Hear Disord, 51 : 226, 1986. 